\title{
Intraoperative middle cerebral artery pressure measurements during superficial temporal artery to middle cerebral artery bypass procedures in patients with cerebral atherosclerotic disease
}

\author{
Fumihiro Matano, MD, PhD, ${ }^{1}$ Yasuo Murai, MD, PhD, ${ }^{1}$ Rokuya Tanikawa, MD, ${ }^{2}$ \\ Hiroyasu Kamiyama, MD, ${ }^{2}$ Kojiro Tateyama, MD, PhD, ${ }^{1}$ Tomonori Tamaki, MD, PhD, \\ Takayuki Mizunari, MD, PhD, ${ }^{1}$ Sunao Mizumura, MD, PhD, ${ }^{3}$ Shiro Kobayashi, MD, PhD, ${ }^{1}$ \\ Akira Teramoto, MD, PhD, ${ }^{1}$ and Akio Morita, MD, PhD ${ }^{1}$
}

'Department of Neurological Surgery, Nippon Medical School; ${ }^{3}$ Department of Radiology, Toho University Omori Medical Center,
Tokyo; and ²Department of Neurosurgery, Teishinkai Hospital, Sapporo, Japan

OBJECTIVE No previous study has monitored middle cerebral artery (MCA) pressure during the superficial temporal artery (STA)-MCA bypass procedure for cerebral atherosclerotic disease. In this paper, the authors describe their method of monitoring MCA pressure and report their initial data on intraoperative MCA pressure and its relationship with hemodynamics prior to and after the bypass procedures.

METHODS The results from a total of 39 revascularization procedures performed between 2004 and 2014 were analyzed. The patient group included 27 men and 12 women, and their mean age at surgery was 67.6 years (range 39-83 years). The authors investigated the MCA pressure via the STA during STA-MCA bypass procedures. After one branch of the STA was anastomosed to the MCA, the other branch was connected to an arterial line, and a clip was placed temporally on the main STA trunk to monitor the pre-anastomosis MCA pressure. Simultaneously, the radial artery (RA) pressure was determined before removing the temporal clip to measure the post-anastomosis MCA pressure. The relationship between MCA pressures and single photon emission computed tomography findings and the risk factors for hyperperfusion after STA-MCA bypass were analyzed.

RESULTS The MCA/RA (\%) pressure was significantly correlated with that of the resting stenotic/normal side cerebral blood flow (CBF) ratio (\%) in the linear regression analysis (slope 1.200, $r^{2}=0.3564, F=20.49, p<0.0001$ ). The intraoperative MCA pressure was $39.3 \%$ of RA pressure in patients with Powers' Stage 2 cerebral atherosclerotic disease. After 1 branch of the STA was anastomosed, the intraoperative MCA pressure increased to $75.3 \%$ of the RA pressure. The rate of increase in pressure was significantly correlated with the increase in the STA diameter in the linear regression analysis (slope $2.59, r^{2}=0.205, F=9.549, p=0.0038$ ). Hyperperfusion occurred in 2 cases. When mean values for these 2 patients were compared with those for the 37 patients without hyperperfusion, significant differences were found in the stenotic/normal side CBF ratio $(p=0.0001)$, pre-anastomosis MCA pressure $(p=0.02)$, rate of increase in pressure $(p=0.02)$, pre-anastomotic MCA/RA pressure ratio $(p=0.01)$, vascular reserve $(p=0.0489)$, and STA diameter ( $p$ $=0.0002$ ).

CONCLUSIONS The measurement of intraoperative MCA pressure may be a useful technique to assess cerebral perfusion and for predicting the risk of hyperperfusion. Monitoring MCA pressure is recommended during STA-MCA bypass procedures for atherosclerotic disease.

http://thejns.org/doi/abs/10.3171/2015.10.JNS151305

KEY WORDS SPECT; cerebral blood flow; middle cerebral artery; superficial temporal artery; vascular disorders

ABBREVIATIONS 3D-SSP = 3D stereotactic surface projection; $\mathrm{CBF}=$ cerebral blood flow; $\mathrm{CPP}=$ cerebral perfusion pressure; ICA = internal carotid artery; ${ }^{123}$-IMP = $\mathrm{N}$-isopropyl [ ${ }^{123}$ ] -p-iodoamphetamine; JET = Japan Extracranial-Intracranial Bypass Trial; $\mathrm{MCA}=$ middle cerebral artery; $\mathrm{RA}=\mathrm{radial}$ artery; $\mathrm{rCBF}=$ regional $\mathrm{CBF} ; \mathrm{ROI}=$ region of interest; SPECT = single photon emission computed tomography; STA = superficial temporal artery.

SUBMITTED June 7, 2015. ACCEPTED October 23, 2015.

INCLUDE WHEN CITING Published online March 4, 2016; DOI: 10.3171/2015.10.JNS151305. 
$\mathrm{T}$ HE role of superficial temporal artery (STA) to middle cerebral artery (MCA) bypass procedures has not been broadly established in adult intracranial vascular pathologies. ${ }^{4,13}$ However, there is supporting evidence for STA-MCA bypass surgery in cases of recurrent transient ischemic attacks with Powers' Stage 2 cerebrovascular reserve capacity. $9,12,16,19,26,27,29$

The main diagnostic tools for cerebral atherosclerotic disease are $N$-isopropyl $\left[{ }^{123} \mathrm{I}\right]$-p-iodoamphetamine (123I-IMP)-single photon emission computed tomography (SPECT) (123I-IMP-SPECT) and cerebral blood flow $(\mathrm{CBF})$ and vascular reserve studies. ${ }^{23,29}$

To date, no study has monitored MCA pressure to assess hemodynamic change during an STA-MCA bypass procedure in patients with cerebral atherosclerotic disease. In this retrospective study, we investigated MCA pressure via the STA during STA-MCA bypass procedures.

In this paper, we first describe our technique of measuring MCA pressure and present the initial intraoperative MCA pressure data for patients with cerebral atherosclerotic disease. We then examine the relationship between MCA pressure and SPECT findings to understand the significance of MCA pressure in STA-MCA bypass surgery. In addition, we analyze the risk factors for hyperperfusion after STA-MCA bypass.

\section{Methods}

The study is reported based on criteria from the STROBE (Strengthening the Reporting of Observational Studies in Epidemiology) statement. The study protocol was approved by the Nippon Medical School Hospital Research Ethics Committee, and written informed consent was obtained from all patients.

\section{Patient Characteristics}

We retrospectively analyzed the results from a total of 39 revascularization procedures performed in patients at our hospitals and associated institutions between 2004 and 2014. The patient group comprised 27 men and 12 women, and the patients' mean age at the time of surgery was 67.6 years (range 39-83 years). We included patients with atherosclerosis and internal carotid artery (ICA) or MCA lesions undergoing either single- or double-bypass procedures. We excluded the patients with bilateral intracranial stenotic lesions. All patients underwent bypass surgery approximately 3 months after the last ischemic event, and the procedure was performed by 1 of 3 surgeons (Y.M., R.T., H.K.), each of whom had more than 15 years of experience in neurological surgery.

\section{Analysis of SPECT Study and Surgical Indication}

The indications for the use of STA-MCA anastomosis for cerebral atherosclerotic disease in our study were based on those detailed in the Japan Extracranial-Intracranial Bypass Trial (JET) protocol. ${ }^{18}$ A preoperative CBF study was performed using ${ }^{123}$ I-IMP-SPECT in all patients. The SPECT study was evaluated by autoradiography ${ }^{17}$ in 21 patients and by the microsphere method ${ }^{21}$ in 18 patients.

The CBF image set was quantified using autoradiography with $222 \mathrm{MBq}$ of ${ }^{123} \mathrm{I}$-IMP administered intravenously at a constant rate over a 1-minute period. SPECT data were acquired 20 minutes after the injection, and blood samples were taken from the antecubital artery 7 minutes before the administration of ${ }^{123} \mathrm{I}$-IMP and 10 minutes after the injection. The SPECT system had a full-width, halfmaximum resolution of $10.4 \mathrm{~mm}$, and used a 3-headed gamma camera (GCA-9300A/HG, Toshiba Co.) equipped with low-energy, high-resolution fan beam collimators and a GMS-5500A/DI processing computer (Toshiba Co.). For the microsphere methods, patients were administered $222 \mathrm{MBq}$ of ${ }^{123}$ I-IMP intravenously at a constant rate over a 45-second period. SPECT data were acquired 26-50 minutes after the injection, and blood samples were taken from the antecubital artery continuously 5 minutes after the injection of ${ }^{123}$ I-IMP. The full-width, half-maximum resolution of the SPECT system was $10.0 \mathrm{~mm}$, and it had a 2-headed gamma camera (Millennium MG, GE Healthcare Japan) equipped with low-energy, general-purpose collimators and a GEniE Xeleris processing computer (AGE Healthcare Japan). We conducted a paired CBF study with an acetazolamide challenge according to the JET study protocol, which corresponded to the 3D stereotactic surface projection (3D-SSP) ${ }^{26}$ In addition to obtaining mean counts of isotope in the region of interest (ROI) on axial images, brain surface images were obtained using the 3D-SSP program. The 3D-SSP method offers quantitative information and 3D displays of $\mathrm{CBF}$ at rest and after an acetazolamide challenge. It also provides information about the vascular reserve and the severity of the hemodynamic brain ischemia. The maximum count data correlated closely with the ROI data at rest and with the acetazolamide SPECT images ( $p<0.0001$ for both). The results of this method indicated that 3D-SSP could simply and objectively evaluate the severity of impaired brain circulation. The cerebrovascular reserve capacity was classified into 3 stages (Stages 0-2) on the basis of vascular reserve capacity calculated from the regional $\mathrm{CBF}(\mathrm{rCBF})$ values at rest and during the acetazolamide challenge. Vascular reserve was defined as follows: ([CBF under acetazolamide $-\mathrm{rCBF}] / \mathrm{rCBF}) \times 100(\%)$. Each of the 15,965 coordinates of the brain surface image were classified as Stage 0 (rCBF is greater than $15 \mathrm{ml} / 100 \mathrm{~g} / \mathrm{min}$ and vascular reserve is greater than $30 \%$ ); Stage 1 (rCBF is less than $34 \mathrm{ml} / 100 \mathrm{~g} / \mathrm{min}$ [80\% normal CBF] but greater than $15 \mathrm{ml} / 100 \mathrm{~g} / \mathrm{min}$ and vascular reserve is less than $30 \%$ but greater than $10 \%$ or $\mathrm{rCBF}$ is greater than $34 \mathrm{ml} / 100$ $\mathrm{g} / \mathrm{min}$ and vascular reserve is less than $30 \%$ but greater than $-30 \%$ ); and Stage 2 (rCBF is less than $34 \mathrm{ml} / 100 \mathrm{~g} /$ min but greater than $15 \mathrm{ml} / 100 \mathrm{~g} / \mathrm{min}$ and vascular reserve is less than $10 \%$ but greater than $-30 \%$ ). We investigated the normal and stenotic side for $\mathrm{CBF}$ at rest, $\mathrm{CBF}$ with an acetazolamide challenge test, and the acetazolamide reactivity. Postoperative hyperperfusion was defined as $\mathrm{CBF}$ greater than $150 \%$ of the CBF value for the normal side.

\section{Surgical Treatment and MCA Pressure}

We dissected 2 branches of the STA, placed a clip proximally on each branch, and then cut the STA diagonally, creating a wide cross-sectional opening to increase the stitching length. We then anastomosed one branch of the STA to the MCA in an end-to-side fashion with 10-0 
nylon thread. The other branch of the STA was then connected to an arterial line, and a clip was placed temporally on the main STA trunk to monitor the pre-anastomosis MCA pressure before completing the second bypass. At the same time, we checked the radial artery (RA) pressure (Fig. 1), and then removed the temporal clip and measured the post-anastomosis MCA pressure.

\section{Statistical Analysis}

The correlations between arterial MCA/RA pressure ratio (\%) and resting stenotic/normal side $\mathrm{CBF}$ pressure ratio (\%) were calculated using linear regression models. The correlation between rate of increase in pressure and STA diameter were also calculated using linear regression models. The relationship between hyperperfusion and these parameters was investigated. Student $\mathrm{t}$-tests were used to assess age, sex, and CBF ratios (stenotic-side MCA territory and normal-side MCA territory), vascular reserve and RA pressures, pre-anastomosis MCA pressure, postanastomosis MCA pressure, pre-anastomosis MCA/RA pressure ratio, STA diameter, and the increase in MCA pressure. Differences were considered significant when $\mathrm{p}<0.05$. All statistical analyses were performed using GraphPad Prism (version 5.0 software package, GraphPad Software).

\section{Results}

On retrospectively analyzing the results from 39 revascularization procedures, we found that ICA and MCA lesions accounted for 22 and 17 cases, respectively, while single bypass was performed in 7 cases and double bypass in 32 cases. Table 1 summarizes the results of SPECT, with intraoperative MCA pressure measurements. The MCA/RA (\%) pressure was significantly correlated with that of the resting stenotic/normal side $\mathrm{CBF}$ ratio (\%) in the linear regression analysis (slope 1.200, $\mathrm{r}^{2}=0.3564, \mathrm{~F}=$ 20.49 , p < 0.0001; Fig. 2 left). When the cases were stratified on the basis of method (autoradiography vs microsphere), the correlations were still significant (for the autoradiography method, slope $1.121, \mathrm{r}^{2}=0.3569, \mathrm{~F}=10.55$, $\mathrm{p}=0.0042$; for the microsphere method, slope 1.121, $\mathrm{r}^{2}=$ $0.2934, \mathrm{~F}=6.644, \mathrm{p}=0.202$ ). There was no statistically significant difference between the MCA/RA pressure ratios (\%) for the ICA lesions and those for the MCA lesions (95\% CI -0.21 to $0.03, \mathrm{p}=0.1589$ ). The intraoperative MCA pressure was $39.3 \%$ of the RA pressure in patients with Stage 2 cerebral atherosclerotic disease. The intraoperative STA pressure was very similar to the RA pressure $(p=0.69)$. After 1 branch of the STA was anastomosed, the intraoperative MCA pressure increased to $75.3 \%$ of RA pressure. Therefore, the increase in the intraoperative MCA pressure was $36.0 \%(29.2 \mathrm{~mm} \mathrm{Hg})$ following the anastomosis of 1 branch of the STA. Moreover, the rate of increase in pressure was significantly correlated with the increase in the STA diameter in the linear regression analysis (slope 2.59, $\mathrm{r}^{2}=0.205, \mathrm{~F}=9.549, \mathrm{p}=0.0038$; Fig. 2 right). Hyperperfusion was observed in 2 of 39 cases. Table 2 provides the results of statistical analysis for the risk of hyperperfusion after STA-MCA bypass. Using the Student t-test, we found significant differences in the risk of hyperperfusion for the stenotic/normal side $\mathrm{CBF}$ ratio (range $0.18-0.5$; mean $0.53 \pm 0.1$ for the hyperperfusion

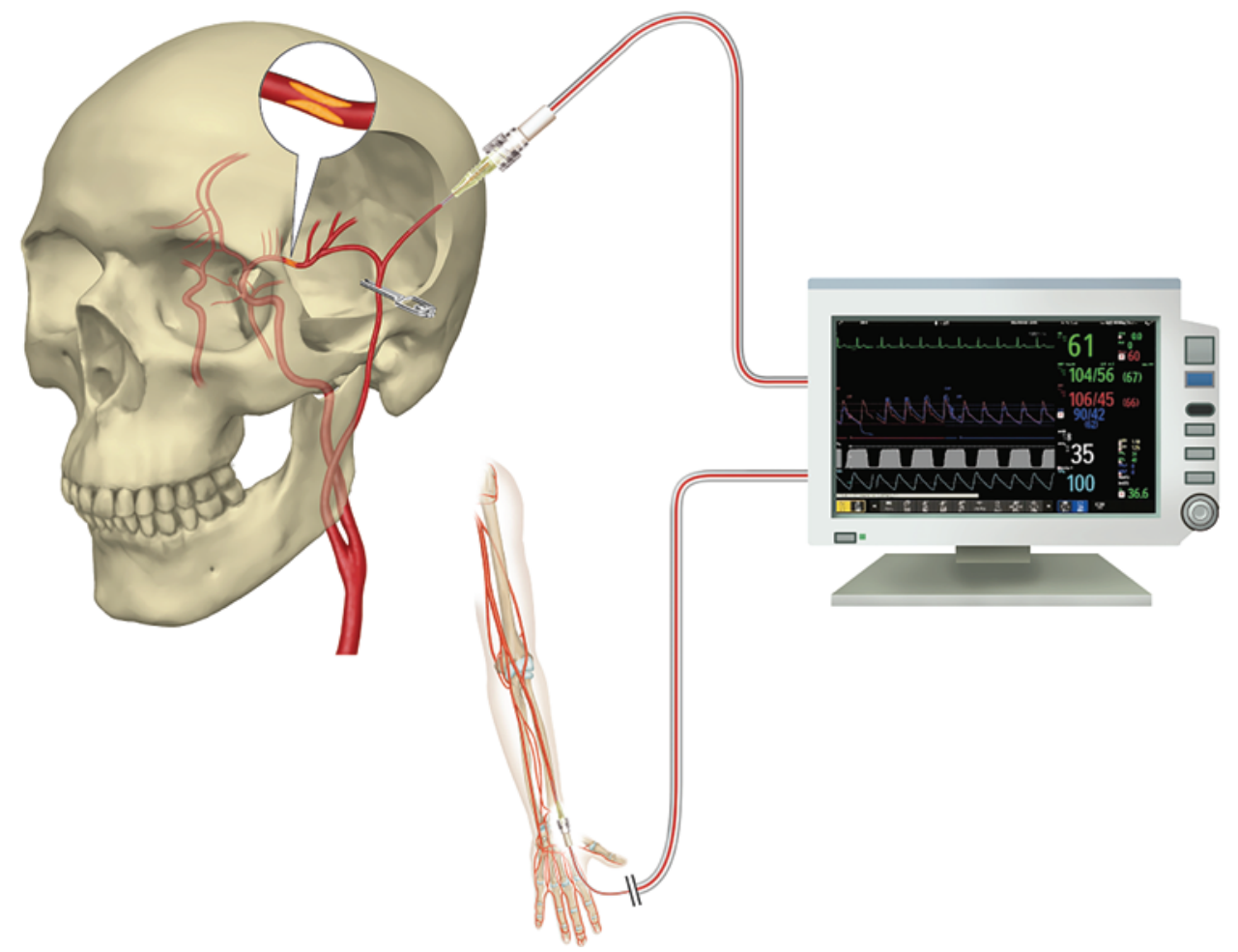

FIG. 1. Illustration showing intraoperative monitoring of MCA and RA pressure. Copyright Fumihiro Matano. Published with permission. 
TABLE 1. Data for preoperative SPECT and intraoperative MCA and RA pressure*

\begin{tabular}{cc}
\hline \multicolumn{1}{c}{ Study } & Mean (SD) \\
\hline SPECT & $32.1(8.6)$ \\
\hline Stenotic side CBF, $\mathrm{ml} / 100 \mathrm{~g} / \mathrm{min}$ & $37.5(8.1)$ \\
\hline Normal side CBF, $\mathrm{ml} / 100 \mathrm{~g} / \mathrm{min}$ & $1.19(6.7)$ \\
\hline Vascular reserve, $\%$ & \\
\hline MCA \& RA pressure & \\
\hline RA, mm Hg & $31.2(14.6)$ \\
\hline MCA, mm Hg & $60.4(16.5)$ \\
\hline Pre-anastomosis & $39.3(18.6)$ \\
\hline Post-anastomosis & $75.30(19)$ \\
\hline MCA/RA, $\%$ & $36.00(22.5)$ \\
\hline Pre-anastomosis
\end{tabular}

group vs $0.87 \pm 0.2$ for the no-hyperperfusion group; $\mathrm{p}=$ 0.0001 ), pre-anastomosis MCA pressure (range 4.0-46.9 $\mathrm{mm} \mathrm{Hg}$; mean $7 \pm 4$ vs $32.5 \pm 15 \mathrm{~mm} \mathrm{Hg}$; $\mathrm{p}=0.02)$, rate of increase in pressure (range $0.08-0.7 ; 0.85 \pm 0.2$ vs 0.46 $\pm 0.1 ; \mathrm{p}=0.02$ ), pre-anastomotic MCA/RA pressure ratio (range 0.07-0.59; mean $0.07 \pm 0.02$ vs $0.41 \pm 0.06 ; \mathrm{p}=$ 0.01 ), vascular reserve (range $-13 \%-9.2 \%$; mean $-8 \% \pm$ 7.1 vs $1.45 \% \pm 6.4 ; \mathrm{p}=0.0489$ ), and STA diameter (range $0.8-2.3$; mean $2.01 \pm 0.3$ vs $1.34 \pm 0.2 ; \mathrm{p}=0.0002$ ).

\section{Discussion}

In this report, we have presented the technique and initial data relevant for intraoperative MCA pressure measurements via the STA in patients with cerebral atherosclerotic disease. We can conclude that because these pressure measurements were related to the preoperative $\mathrm{CBF}$ results obtained by SPECT and were lower than the lower limit of $\mathrm{CBF}$ autoregulation, they may reflect cerebral perfusion in the patients with Stage 2 cerebral atherosclerotic disease. Moreover, intraoperative monitoring of MCA pressure and preoperative checking of the STA diameter may aid in the prediction of cerebral hyperperfusion syndrome.

The Carotid Occlusion Surgery Study (COSS), which examined the prevention of cerebral ischemia in patients with atherosclerotic disease, concluded that the indications for STA-MCA bypass required reconsideration because of the number of perioperative ischemic complications. ${ }^{4,31}$ However, improved hemodynamics in study participants who survived STA-MCA bypass surgery without perioperative stroke were associated with lower risk of recurrent stroke compared with the risk for patients receiving medical therapy in the nonsurgical group. Therefore, if we can reduce the rate of perioperative complications, STA-MCA bypass has the potential to reduce the cerebral infarction rate. To prevent perioperative ischemic complications, a favorable blood supply may be required. However, vascular reconstructions can occasionally cause a rapid increase in CBF, resulting in cerebral hyperperfusion syndrome. ${ }^{14,15}$ Because hyperperfusion syndrome is associated with worse outcomes, ${ }^{7,32}$ it is important that it be avoided following the STA-MCA bypass procedure. Although we know that patients with poorer cerebrovascular reactivity have a higher risk for hyperperfusion syndrome, ${ }^{34}$ other predictive factors have not been adequately reported; therefore, we investigated MCA pressure calculated through a single anastomosed branch of the STA during the STA-MCA bypass procedure. To the best of our knowledge, no reports have described a technique for calculating the intraoperative MCA pressure to date.

Lee et al. ${ }^{25}$ reported on intraoperative MCA and STA flow in patients with high-volume moyamoya disease. The authors successfully showed that intraoperative flow data aid in the understanding of the complex hemodynamic pathology of the vasculopathy and of the mechanism by which STA-MCA bypass surgery changed the hemodynamics. However, as predicted by Bernoulli's principle, ${ }^{10}$ the blood flow in the distal stenosis was faster than that in the proximal stenosis. Therefore, it is thought that cerebral arterial pressure evaluation is more appropriate than cerebral arterial flow evaluation for analyzing cerebral
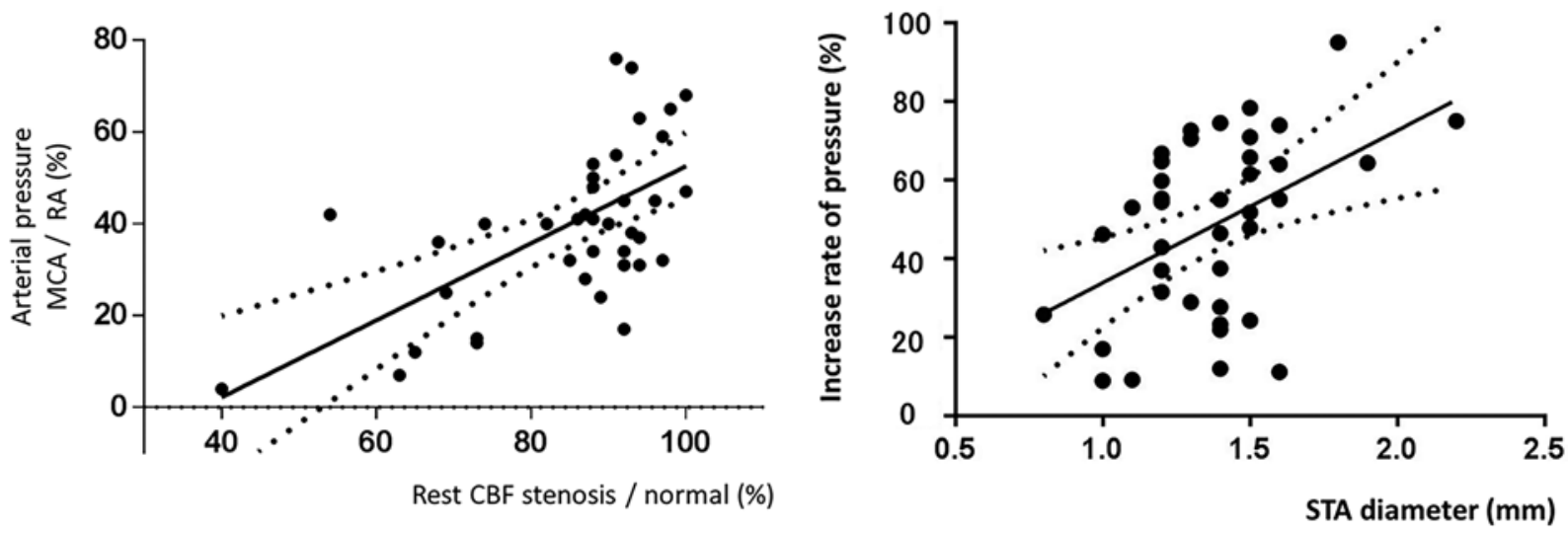

FIG. 2. Left: Scatterplot showing that the MCA/RA pressure (\%) was significantly correlated with the resting CBF stenosis side/ normal side (\%) in linear regression analysis (slope 1.200, $r^{2}=0.3564, F=20.49, p<0.0001$ ). Right: Scatterplot showing that the rate of increased pressure was significantly correlated with that of STA diameter in linear regression analysis (slope $2.59, r^{2}=$ $0.205, F=9.549, p=0.0038$ ). Dotted lines denote the $95 \%$ Cls. 
TABLE 2. Statistical analysis of the risk factors for hyperperfusion*

\begin{tabular}{lccr}
\hline \multirow{2}{*}{ Variable } & \multicolumn{2}{c}{ Hyperperfusion } & \multirow{2}{*}{ p Value } \\
\cline { 2 - 3 } & Present $(\mathrm{n}=2)$ & Absent $(\mathrm{n}=37)$ & 0.69 \\
\hline Age in yrs & $70.5(11)$ & $67.3(4.9)$ & $>0.99$ \\
\hline Male sex, no. & $2(5 \%)$ & $25(64 \%)$ & 0.0001 \\
\hline Stenotic/normal side CBF ratio & $0.53(0.1)$ & $0.87(0.2)$ & 0.0489 \\
\hline Vascular reserve, $\%$ & $-8(7.1)$ & $1.45(6.4)$ & 0.17 \\
\hline RA pressure, mm Hg & $94(14)$ & $79.4(17)$ & 0.02 \\
\hline Pre-anastomosis MCA pressure, $\mathrm{mm} \mathrm{Hg}$ & $7(4)$ & $32.5(15)$ & 0.94 \\
\hline Post-anastomosis MCA pressure, $\mathrm{mm} \mathrm{Hg}$ & $59.5(16)$ & $60.4(28)$ & 0.01 \\
\hline Pre-anastomosis MCA pressure/RA pressure ratio & $0.07(0.2)$ & $0.41(0.06)$ & 0.0002 \\
\hline STA diameter, mm & $2.01(0.3)$ & $1.34(0.2)$ & 0.02 \\
\hline Rate of increase in MCA pressure & $0.85(0.2)$ & $0.46(0.1)$ & \\
\hline
\end{tabular}

* Values are mean (SD) unless otherwise indicated.

perfusion. Furthermore, there are no reports concerning cerebral flow and pressure in patients with cerebral atherosclerotic disease.

We found that the intraoperative pre-anastomosed MCA pressure obtained via the STA statistically correlated with the preoperative $\mathrm{CBF}$ as determined by SPECT. CBF is relatively independent of changes in mean arterial pressure within a certain range..$^{22,30}$ The lower limit of CBF autoregulation corresponds to mean arterial pressures of approximately $50-60 \mathrm{~mm} \mathrm{Hg.}{ }^{1,20,24,30}$ Stump pressure provides an objective measurement of collateral cerebral circulation. The patients with a stump pressure less than $25 \mathrm{~mm} \mathrm{Hg}$ and contralateral carotid occlusion have been found to exhibit electroencephalographic changes. ${ }^{5}$ AbuRahma et al. ${ }^{2}$ reported that stump pressure and retrograde internal flow were statistically significant and predict cerebral hypoperfusion. They concluded that in patients with a stump pressure greater than $40 \mathrm{~mm} \mathrm{Hg}$, carotid shunting during carotid endarterectomy is not always necessary. ${ }^{3}$ In the present study, the mean pressures of the pre- and post-anastomosed MCAs were $31.2 \mathrm{~mm} \mathrm{Hg}$ (SD $15.47 \mathrm{~mm} \mathrm{Hg}$ ) and $60.4 \mathrm{~mm}$ $\mathrm{Hg}$ (SD $16.54 \mathrm{~mm} \mathrm{Hg}$ ), respectively. Provisionally, using the intraoperative pre-anastomosed MCA pressure to approximate the cerebral perfusion pressure (CPP) and RA pressure to approximate the mean arterial pressure, the CPP was $39.3 \%$ of the mean arterial pressure in patients with Stage 2 cerebral atherosclerotic disease. ${ }^{12}$ After one branch of the STA had been anastomosed, the CPP increased to $75.3 \%$ of the mean arterial pressure, with an increase in the CPP of $36.0 \%$ (29.2 $\mathrm{mm} \mathrm{Hg}$ ). Collectively, the pre-anastomosed MCA pressure was lower than the lower limits of $\mathrm{CBF}$ autoregulation, and MCA pressure was up to the threshold of $\mathrm{CBF}$ autoregulation after one branch of the STA had been anastomosed (Fig. 3). Thus, the present study showed that intraoperative pre-anastomosed MCA pressure may reflect cerebral perfusion.

We found that the risk of hyperperfusion was associated with the stenotic/normal side CBF ratio $(\mathrm{p}=0.0001)$, vascular reserve $(\mathrm{p}=0.0489)$, pre-anastomosis MCA pressure $(\mathrm{p}=0.02)$, pre-anastomotic MCA/RA pressure ratio $(p=0.01)$, rate of increase in pressure $(p=0.02)$, and STA diameter $(p=0.0002)$ in this study. The finding that low perfusion and poorer cerebrovascular reactivity were as- sociated with the risk of hyperperfusion is consistent with findings of previous studies. ${ }^{6,34}$ There are few reports of the diameter of the donor vessel and the blood supply as risk factors for hyperperfusion. When we analyzed the STA diameter at $2 \mathrm{~cm}$ from the bifurcation, the intraoperative STA pressure was almost the same as the RA pressure ( $\mathrm{p}=0.69$; data not shown). The increased MCA pressure correlated positively with the STA diameter. However, our technique requires the sacrifice of both STA branches, which has been shown to be associated with a higher incidence of wound complications than the single bypass procedure. ${ }^{33}$ Therefore, we must take precautions to protect the skin while performing our methods. To prevent impaired blood flow to the skin, we cut the frontal branch of the STA distal to the bifurcation to retain retrograde blood flow; resutured the branch of the STA, when possible; debrided the wound margin of the parietal part of the scalp, about $2 \mathrm{~mm}$; and loosely sutured with $4-0$ nylon thread.

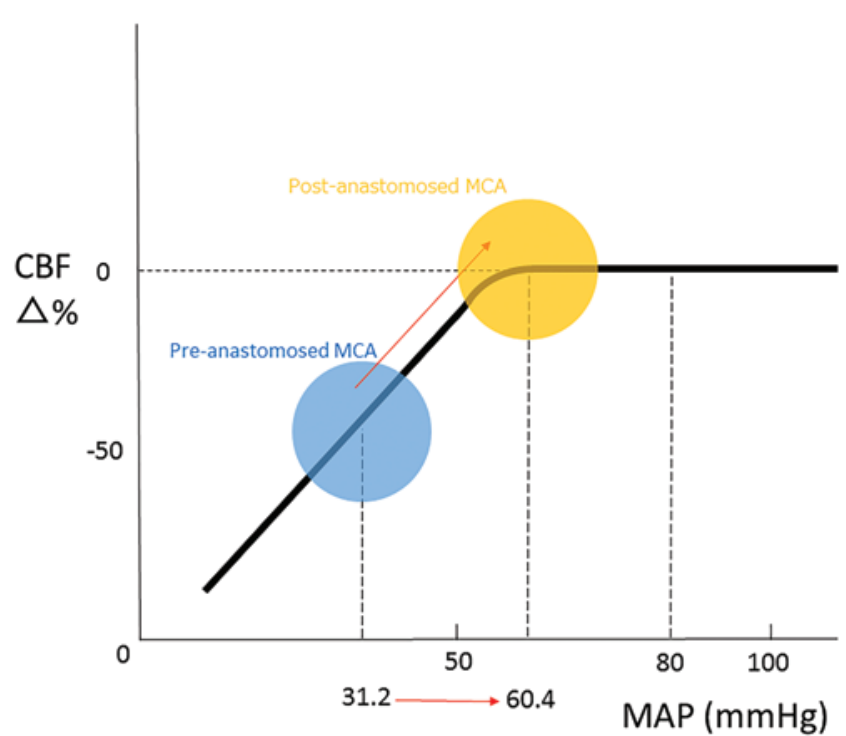

FIG. 3. Illustrative graph showing the relationship between the lower limits of CBF autoregulation and the intraoperative MCA pressure. MAP $=$ mean arterial pressure. 
In addition, arterial line cannulation was carefully carried out using a microscope to prevent dissection of the STA and air embolism. No complications related to this procedure, such as wound complication, STA dissection, air embolism, or ischemic lesion as evaluated by MRI and MR angiography, were encountered within postoperative Day 3.

With respect to blood supply, we consider double anastomoses to be more effective for preventing perioperative ischemia than single bypass. ${ }^{8,23}$ However, in patients with low preoperative CBF, low pre-anastomosed MCA pressure, wide STA diameter, and increased MCA pressures after the initial bypass, double anastomoses may induce excessive flow and a single bypass should be appropriate.

In addition, special attention should be focused on postoperative hyperperfusion in high-risk cases, as established from intraoperative data using our methods. We can prevent postoperative hyperperfusion with aggressive blood pressure control measures, such as the administration of edaravone, which lowered the incidence of post-carotid endarterectomy hyperperfusion in treated patients $(7 \%)$ compared with controls $(67 \%),{ }^{28}$ or minocycline, which lowered the incidence of post-bypass hyperperfusion in the treated group ( 0 of 60 cases) compared with the control group (4 of 49 cases, $8.16 \%$ ) of patients with moyamoya disease. ${ }^{11}$ There have been no previous reports focusing on intraoperative MCA pressure in patients with atherosclerotic disease, and it would be helpful to further examine intraoperative MCA pressure results through additional study.

\section{Limitations}

This study is limited by the relatively small sample size, which precluded comprehensive statistical correlations. Therefore, we did not perform multivariate logistic regression analysis and were instead restricted to univariate analyses. Moreover, in the present study, postoperative hyperperfusion occurred in only 2 patients; additional cases are required to support our findings. STA-MCA bypass for atherosclerotic disease is uncommon. Although only 2 patients exhibited postoperative hyperperfusion in our study, this represents a complication rate of over 5\%, a frequency that cannot be considered low; thus, consideration for preventing such complications is required. Judging from our statistical results, the combination of low cerebral perfusion with an abundant blood supply may be a risk factor for hyperperfusion. Finally, MCA pressure is not the best direct measure of CPP and does not always correlate with perfusion or clinical improvement/deterioration.

\section{Conclusions}

Intraoperative MCA pressure may be a useful technique for assessing cerebral perfusion and for predicting the risk of hyperperfusion. Monitoring MCA pressure is recommended during STA-MCA bypass procedures for atherosclerotic disease.

\section{References}

1. Aaslid R, Lindegaard KF, Sorteberg W, Nornes H: Cerebral autoregulation dynamics in humans. Stroke 20:45-52, 1989
2. AbuRahma AF, Mousa AY, Stone PA: Shunting during carotid endarterectomy. J Vasc Surg 54:1502-1510, 2011

3. AbuRahma AF, Mousa AY, Stone PA, Hass SM, Dean LS, Keiffer T: Correlation of intraoperative collateral perfusion pressure during carotid endarterectomy and status of the contralateral carotid artery and collateral cerebral blood flow. Ann Vasc Surg 25:830-836, 2011

4. Carlson AP, Yonas H, Chang YF, Nemoto EM: Failure of cerebral hemodynamic selection in general or of specific positron emission tomography methodology?: Carotid Occlusion Surgery Study (COSS). Stroke 42:3637-3639, 2011

5. Cherry KJ Jr, Roland CF, Hallett JW Jr, Gloviczki P, Bower $\mathrm{TC}$, Toomey BJ, et al: Stump pressure, the contralateral carotid artery, and electroencephalographic changes. Am J Surg 162:185-189, 1991

6. Chiu TL, Tsai ST, Chiu CH: Prediction of flow augmentation and complications of extracranial-intracranial bypass in symptomatic cerebrovascular diseases. J Clin Neurosci 19:814-819, 2012

7. Coutts SB, Hill MD, Hu WY: Hyperperfusion syndrome: toward a stricter definition. Neurosurgery 53:1053-1060, 2003

8. Duckworth EA, Rao VY, Patel AJ: Double-barrel bypass for cerebral ischemia: technique, rationale, and preliminary experience with 10 consecutive cases. Neurosurgery 73 (1 Suppl Operative):ons30-ons38, 2013

9. Fluri F, Engelter S, Lyrer P: Extracranial-intracranial arterial bypass surgery for occlusive carotid artery disease. Cochrane Database Syst Rev (2):CD005953, 2010

10. Franklin WS, Deimel RF: Pressure energy in an incompressible fluid and Bernoulli's principle. Science 62:397, 1925

11. Fujimura M, Niizuma K, Inoue T, Sato K, Endo H, Shimizu $\mathrm{H}$, et al: Minocycline prevents focal neurological deterioration due to cerebral hyperperfusion after extracranialintracranial bypass for moyamoya disease. Neurosurgery 74:163-170, 2014

12. Grubb RL Jr, Derdeyn CP, Fritsch SM, Carpenter DA, Yundt $\mathrm{KD}$, Videen TO, et al: Importance of hemodynamic factors in the prognosis of symptomatic carotid occlusion. JAMA 280:1055-1060, 1998

13. Hänggi D, Steiger HJ, Vajkoczy P: The role of MCA-STA bypass surgery after COSS and JET: the European point of view. Acta Neurochir Suppl 119:77-78, 2014

14. Heros RC, Scott RM, Kistler JP, Ackerman RH, Conner ES: Temporary neurological deterioration after extracranialintracranial bypass. Neurosurgery 15:178-185, 1984

15. Higashi S, Matsuda H, Fujii H, Ito H, Yamashita J: Luxury perfusion syndrome confirmed by sequential studies of regional cerebral blood flow and volume after extracranial to intracranial bypass surgery: case report. Neurosurgery 25:85-89, 1989

16. Holohan TV: Extracranial-intracranial bypass to reduce the risk of ischemic stroke. CMAJ 144:1457-1465, 1991

17. Iida $H$, Itoh $H$, Nakazawa $M$, Hatazawa J, Nishimura $H$, Onishi Y, et al: Quantitative mapping of regional cerebral blood flow using iodine-123-IMP and SPECT. J Nucl Med 35:2019-2030, 1994

18. Jinnouchi J, Toyoda K, Inoue T, Fujimoto S, Gotoh S, Yasumori K, et al: Changes in brain volume 2 years after extracranial-intracranial bypass surgery: A preliminary subanalysis of the Japanese EC-IC trial. Cerebrovasc Dis 22:177-182, 2006

19. Kanamaru K, Araki T, Kawakita F, Hamada K, Kanamaru $\mathrm{H}$, Matsuura K, et al: STA-MCA bypass for the treatment of ischemic stroke. Acta Neurochir Suppl (Wien) 112:55-57, 2011

20. Kontos HA, Wei EP, Navari RM, Levasseur JE, Rosenblum WI, Patterson JL Jr: Responses of cerebral arteries and arterioles to acute hypotension and hypertension. Am J Physiol 234:H371-H383, 1978 
21. Kuhl DE, Barrio JR, Huang SC, Selin C, Ackermann RF, Lear JL, et al: Quantifying local cerebral blood flow by Nisopropyl-p-[123I]iodoamphetamine (IMP) tomography. J Nucl Med 23:196-203, 1982

22. Kunz A, Iadecola C: Cerebral vascular dysregulation in the ischemic brain. Handb Clin Neurol 92:283-305, 2009

23. Kuroda S, Kawabori M, Hirata K, Shiga T, Kashiwazaki D, Houkin K, et al: Clinical significance of STA-MCA double anastomosis for hemodynamic compromise in post-JET/ COSS era. Acta Neurochir (Wien) 156:77-83, 2014

24. Lassen NA: Cerebral blood flow and oxygen consumption in man. Physiol Rev 39:183-238, 1959

25. Lee M, Guzman R, Bell-Stephens T, Steinberg GK: Intraoperative blood flow analysis of direct revascularization procedures in patients with moyamoya disease. J Cereb Blood Flow Metab 31:262-274, 2011

26. Mizumura S, Nakagawara J, Takahashi M, Kumita S, Cho K, Nakajo H, et al: Three-dimensional display in staging hemodynamic brain ischemia for JET study: objective evaluation using SEE analysis and 3D-SSP display. Ann Nucl Med 18:13-21, 2004

27. Murai Y, Mizunari T, Takagi R, Amano Y, Mizumura S, Komaba Y, et al: Analysis of ischemic cerebral lesions using 3.0-T diffusion-weighted imaging and magnetic resonance angiography after revascularization surgery for ischemic disease. Clin Neurol Neurosurg 115:1063-1070, 2013

28. Ogasawara K, Inoue T, Kobayashi M, Endo H, Fukuda T, Ogawa A: Pretreatment with the free radical scavenger edaravone prevents cerebral hyperperfusion after carotid endarterectomy. Neurosurgery 55:1060-1067, 2004

29. Ogasawara K, Ogawa A: [JET study (Japanese EC-IC Bypass Trial).] Nihon Rinsho 64 (Suppl 7):524-527, 2006 (Jpn)

30. Paulson OB, Strandgaard S, Edvinsson L: Cerebral autoregulation. Cerebrovasc Brain Metab Rev 2:161-192, 1990

31. Powers WJ, Clarke WR, Grubb RL Jr, Videen TO, Adams HP Jr, Derdeyn CP: Extracranial-intracranial bypass surgery for stroke prevention in hemodynamic cerebral ischemia: the Carotid Occlusion Surgery Study randomized trial. JAMA 306:1983-1992, 2011 [Erratum in JAMA 306:2672, 2011]
32. Stiver SI, Ogilvy CS: Acute hyperperfusion syndrome complicating EC-IC bypass. J Neurol Neurosurg Psychiatry 73:88-89, 2002

33. Takanari K, Araki Y, Okamoto S, Sato H, Yagi S, Toriyama $\mathrm{K}$, et al: Operative wound-related complications after cranial revascularization surgeries. J Neurosurg 123:11451150,2015

34. Yamaguchi K, Kawamata T, Kawashima A, Hori T, Okada Y: Incidence and predictive factors of cerebral hyperperfusion after extracranial-intracranial bypass for occlusive cerebrovascular diseases. Neurosurgery 67:1548-1554, 2010

\section{Disclosures}

The authors report no conflict of interest concerning the materials or methods used in this study or the findings specified in this paper.

\section{Author Contributions}

Conception and design: Matano, Mizumura. Acquisition of data: Matano, Murai, Tanikawa, Kamiyama, Tateyama, Tamaki. Analysis and interpretation of data: Matano, Murai, Mizumura. Drafting the article: Matano, Murai, Mizumura. Critically revising the article: Murai, Tanikawa, Mizumura, Kobayashi, Teramoto, Morita. Reviewed submitted version of manuscript: Tanikawa, Kamiyama, Tateyama, Tamaki, Mizunari, Mizumura, Kobayashi, Teramoto, Morita. Statistical analysis: Matano, Morita. Administrative/technical/material support: Tanikawa, Kamiyama, Tateyama, Tamaki, Mizunari, Mizumura, Kobayashi, Morita. Study supervision: Murai, Kamiyama, Mizunari, Mizumura, Kobayashi, Teramoto, Morita.

\section{Correspondence}

Fumihiro Matano, Department of Neurological Surgery, Nippon Medical School, 1-1-5 Sendagi, Bunkyo-ku, Tokyo 113-8603, Japan.email: s00-078@nms.ac.jp. 